\title{
Molecular subtypes are prognostic for N3 breast cancer patients in the modern therapeutic era
}

\author{
ÖZLEM YERSAL ${ }^{1}$, MUHAMMED ALI KAPLAN ${ }^{2}$, ABDURRAHMAN IŞIKDOĞAN $^{2}$, NURIYE ÖZDEMIR ${ }^{3}$, \\ MEHMET ALIUSTAOĞLU ${ }^{4}$, SABRI BARUTCA ${ }^{1}$, HALIL İBRAHIM ERDOĞDU ${ }^{5}$ and NEZIH MEYDAN ${ }^{1}$ \\ ${ }^{1}$ Department of Medical Oncology, Adnan Menderes University Faculty of Medicine, Aydin 09010; \\ ${ }^{2}$ Department of Medical Oncology, Dicle University Faculty of Medicine, Diyarbakir 21280; \\ ${ }^{3}$ Department of Medical Oncology, Numune Training and Research Hospital, Ankara 06230; \\ ${ }^{4}$ Department of Medical Oncology, Dr Lütfi Kirdar Kartal Training and Research Hospital, İstanbul 34865; \\ ${ }^{5}$ Department of Pathology, Adnan Menderes University Faculty of Medicine, Aydin 09010, Turkey
}

Received May 15, 2018; Accepted October 30, 2018

DOI: $10.3892 / \mathrm{mco} .2018 .1771$

\begin{abstract}
Nodal (N) status and molecular subtypes are well-known prognostic factors for breast cancer patients. The aim of the present study was to evaluate whether there was a prognostic role of molecular subtypes for pN3a breast cancer patients in the modern therapeutic era. The present study retrospectively evaluated a total of 521 breast cancer patients who had 10 or more metastatic lymph nodes and received adjuvant systemic therapy at the Oncology Department of four different centers in Turkey between 2000-2015. Patients were divided into four molecular subtypes by immunohistochemical staining. There were no significant differences in relapse rates according to the molecular subtypes $(\mathrm{P}=0.07)$. The five year disease free survival rate was $62 \%$ for the whole study population, $67 \%$ for Luminal A tumors, $53 \%$ for Luminal B tumors, $64 \%$ for human epidermal growth factor receptor 2-positive tumors and $56 \%$ for triple negative tumors. Luminal A patients had a better progression free survival when compared with Luminal $B(P=0.026)$ and triple negative $(\mathrm{P}=0.07)$ patients. pT stage $(\mathrm{P}<0.001)$, and breast cancer subtype $(\mathrm{P}<0.001)$, remained significant independent factors for disease free survival. Therefore, breast cancer subtypes are still prognostic for patients with $\mathrm{pN} 3$ breast cancer.
\end{abstract}

\section{Introduction}

According to the American Joint Committee on Cancer (AJCC) TNM staging system, pathological lymph node status 3 (pN3a) for breast cancer is defined as 10 or more metastatic lymph node involvement in pathologic evaluation (1). Nodal (N)

Correspondence to: Dr Özlem Yersal, Department of Medical Oncology, Adnan Menderes University Faculty of Medicine, Cumhuriyet Mahallesi, 1991 Sokak, Aydin 09010, Turkey

E-mail: yersal1978@yahoo.com

Key words: breast cancer, biology, prognosis status is a strong and independent negative prognostic factor and pN3a patients have the worst prognosis among breast cancer patients without distant metastases (2).

Older chemotherapy regimens resulted in poor clinical outcome 22-41\% 5-year disease-free survival (DFS) and $39-41 \%$ 5-year overall survival (OS) rates in patients with $\mathrm{N} 3 \mathrm{a}$ disease (3-5); however, the outcome of N3a patients has been favorably improved over years with recent treatment modalities and 5-year DFS rate and OS probability have been reported to reach 66 and $81 \%$ respectively (6).

Because of the limitations of traditional prognostic factors (such as tumor size, $\mathrm{N}$ involvement, nuclear grade, histologic type, molecular markers, and surgical margins), recent studies have focused on defining biological characteristics of disease to provide better risk stratification $(7,8)$. Breast cancer is classified into distinct biological subtypes as a consequence of global gene expression profiling studies $(9,10)$. These subtypes have subsequently been shown to correlate with prognosis, locoregional recurrence and response to systemic therapy. The Her2-positive and basal-like subtypes had the poorest prognosis. The luminal subtypes are the most heterogeneous group as the Luminal A subtype had better prognosis compared with the other subtypes, and the Luminal B subtype had an intermediate outcome (11). However, it remains unclear whether distinct molecular subtypes have different prognosis in $\mathrm{pN} 3 \mathrm{a}$ patients who are already at high risk for recurrence because of extensive $\mathrm{N}$ involvement.

In the present study, we aimed to evaluate prognostic value of molecular subtypes in breast cancer patients with $\mathrm{pN} 3 \mathrm{a} \mathrm{N}$ involvement without distant metastasis, in the modern therapeutic era.

\section{Materials and methods}

Patients. We retrospectively evaluated 521 breast cancer patients who had 10 or more metastatic lymph nodes and received adjuvant systemic therapy at the oncology department of four centers from Turkey between 2000 and 2015.Patient (age, menopause), tumor (size, grade, lymphatic invasion, vascular invasion, hormone receptors, Her2 expression) and treatment 
Table I. Patient characteristics.

\begin{tabular}{|c|c|}
\hline Characteristics & Total no. (\%) \\
\hline \multicolumn{2}{|l|}{ Age, years } \\
\hline$\leq 35$ & $58(11.1)$ \\
\hline$>35$ & 463 (88.9) \\
\hline \multicolumn{2}{|l|}{ Menopause } \\
\hline Pre & $226(43.4)$ \\
\hline Post & $276(53.0)$ \\
\hline Unknown & $19(3.6)$ \\
\hline \multicolumn{2}{|l|}{ Tumor location } \\
\hline Right & $266(51.1)$ \\
\hline Left & 255 (48.9) \\
\hline \multicolumn{2}{|l|}{ ER } \\
\hline Positive & $349(67)$ \\
\hline Negative & $172(33)$ \\
\hline \multicolumn{2}{|l|}{ PR } \\
\hline Positive & $330(63.3)$ \\
\hline Negative & $191(36.7)$ \\
\hline \multicolumn{2}{|l|}{ Her2 } \\
\hline Positive & $218(41.8)$ \\
\hline Negative & 303 (58.2) \\
\hline \multicolumn{2}{|l|}{ Subtype } \\
\hline Luminal A & 247 (47.4) \\
\hline Luminal B & $139(26.7)$ \\
\hline Her2 positive & $81(15.5)$ \\
\hline Triple negative & $54(10.4)$ \\
\hline \multicolumn{2}{|c|}{ Metastatic lymph node } \\
\hline $10-20$ & $410(78.7)$ \\
\hline $21-30$ & $72(13.8)$ \\
\hline$>31$ & $39(7.5)$ \\
\hline \multicolumn{2}{|l|}{ Tumor } \\
\hline $\mathrm{T} 1-\mathrm{T} 2$ & 308 (59) \\
\hline T3-T4 & $191(36.6)$ \\
\hline Unknown & $22(4.4)$ \\
\hline \multicolumn{2}{|l|}{ Operation } \\
\hline Mastectomy & $447(85.8)$ \\
\hline $\mathrm{BCS}$ & $74(14.2)$ \\
\hline
\end{tabular}

ER, estrogen receptor; $\mathrm{PR}$, progesterone receptor; $\mathrm{BCS}$, breast conservative surgery.

related (surgery, adjuvant chemotherapy, radiotherapy, endocrine therapy and trastuzumab) characteristics were recorded from patients files.

Patients who received neoadjuvant chemotherapy were excluded from the study. All patients intended to receive anthracycline based regimen followed by a taxane therapy and then radiotherapy. Patients with Her2 expression score $3(+)$ with immunohistochemistry (IHC) or 2(+) with IHC and fluorescent in situ hybridization (FISH) positive, also received adjuvant trastuzumab therapy if, they were diagnosed after June 2007 with the approval of adjuvant use of trastuzumab by Turkish Ministry of Health. Ki-67 level $<14 \%$ considered as low expression while values $\geq 14 \%$ is considered high

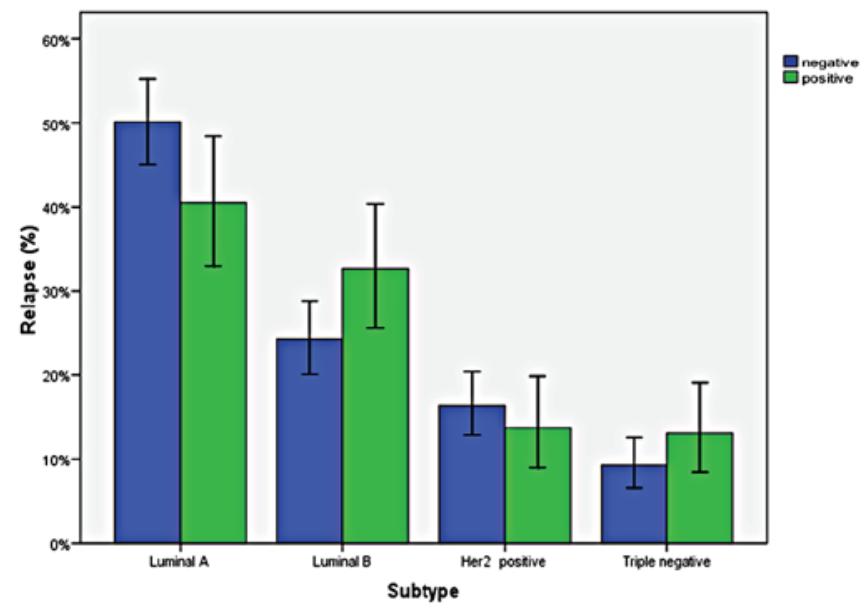

Figure 1. Percentage of patients according to recurrence status by subtype.

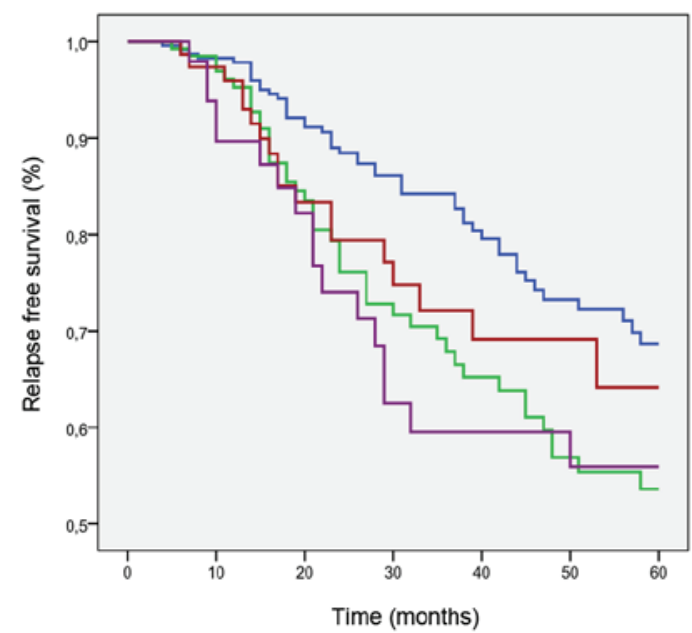

Subtype

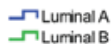
$\rightarrow$ Her2 positive NTriple negative

Figure 2. Kaplan-Meier curves for disease free survival according to the breast cancer subtypes.

expression. Tumors were regarded as positive for estrogen receptor $(\mathrm{ER})$ and progesterone receptor $(\mathrm{PR})$ when $\geq 1 \%$ of the tumor cells showed nuclear staining and patients with hormone positive tumors also received endocrine therapy. The patients were divided into four groups: Luminal A subtype (ER+ and/or PR+, Her2- and Ki-67<14\%), Luminal B subtype (ER+ and/or PR+ and Her2+ or Ki-67>14\%), Her2 positive subtype (ER- and PR-, Her2+), and triple negative subtype (ER-, PR-, Her2-). The present study was approved by Dicle University Ethics Committee (Diyarbakir, Turkey).

Statistical analysis. DFS was estimated as the duration of time from surgery date until first relapse (local, regional or distant) or death from any cause. OS was defined from the date of surgery to the date of death from any cause; surviving patients were censored at the date of last follow-up. The DFS and OS rates were calculated by using Kaplan-Meier method. Cox regression analysis was used to analyze the impact of clinical/pathological characteristics on survival. $\mathrm{P}<0.05$ was considered to indicate a statistically significant difference. Statistical analysis was performed with SPSS for MacOS version 24.0 (IBM Corp., Armonk, NY, USA). 
Table II. Factors associated with disease free survival.

\begin{tabular}{|c|c|c|c|c|}
\hline \multirow[b]{2}{*}{ Variables } & \multicolumn{2}{|c|}{ Univariate } & \multicolumn{2}{|c|}{ Multivariate } \\
\hline & HR & P-value & HR & P-value \\
\hline $\begin{array}{l}\text { Age, years } \\
\leq 35 \\
>35\end{array}$ & $\begin{array}{c}1 \\
0.93\end{array}$ & 0.80 & & \\
\hline $\begin{array}{l}\text { Menopause } \\
\text { Pre } \\
\text { Post }\end{array}$ & $\begin{array}{c}1 \\
0.79\end{array}$ & 0.17 & $\begin{array}{c}1 \\
0.91\end{array}$ & 0.67 \\
\hline $\begin{array}{l}\text { Surgery } \\
\text { BCS } \\
\text { TM }\end{array}$ & $\begin{array}{c}1 \\
0.54\end{array}$ & $0.04^{\mathrm{a}}$ & $\begin{array}{c}1 \\
0.77\end{array}$ & 0.46 \\
\hline $\begin{array}{l}\text { Grade } \\
1 \\
2 \\
3\end{array}$ & $\begin{array}{c}1 \\
0.97 \\
1.04\end{array}$ & $\begin{array}{l}0.95 \\
0.90\end{array}$ & & \\
\hline $\begin{array}{l}\text { Hormone receptor } \\
\text { Negative } \\
\text { Positive }\end{array}$ & $\begin{array}{c}1 \\
0.78\end{array}$ & 0.16 & & \\
\hline $\begin{array}{l}\text { Her2 } \\
\text { Negative } \\
\text { Positive }\end{array}$ & $\begin{array}{c}1 \\
1.29\end{array}$ & 0.12 & & \\
\hline $\begin{array}{l}\text { Lymphatic invasion } \\
\text { Negative } \\
\text { Positive }\end{array}$ & $\begin{array}{c}1 \\
1.34\end{array}$ & 0.16 & $\begin{array}{c}1 \\
1.33\end{array}$ & 0.182 \\
\hline $\begin{array}{c}\text { T stage } \\
1\end{array}$ & 1 & & 1 & \\
\hline $\begin{array}{l}2 \\
3 \\
4\end{array}$ & $\begin{array}{l}1.10 \\
1.13 \\
2.97\end{array}$ & $\begin{array}{l}0.71 \\
0.66 \\
0.001^{\mathrm{c}}\end{array}$ & $\begin{array}{l}1.13 \\
1.06 \\
2.77\end{array}$ & $\begin{array}{l}0.70 \\
0.85 \\
0.009^{b}\end{array}$ \\
\hline Subtype & & & 1 & \\
\hline $\begin{array}{l}\text { Luminal B } \\
\text { Her2 (+) } \\
\text { Triple (-) }\end{array}$ & $\begin{array}{l}1 \\
1.53 \\
1.33 \\
1.56\end{array}$ & $\begin{array}{l}0.02^{\mathrm{a}} \\
0.27 \\
0.08\end{array}$ & $\begin{array}{l}1 \\
1.5 \\
1.2 \\
1.9\end{array}$ & $\begin{array}{l}0.04^{\mathrm{a}} \\
0.57 \\
0.04\end{array}$ \\
\hline
\end{tabular}

${ }^{\mathrm{a}} \mathrm{P}<0.05 ;{ }^{\mathrm{b}} \mathrm{P}<0.01 ;{ }^{\mathrm{c}} \mathrm{P}<0.001$. HR, hazard ratio; BCS, breast conservative surgery; TM, total mastectomy; Her2, human epidermal growth factor receptor 2 .

\section{Results}

Patient characteristics. The clinical and histopathological features of the patients are shown in Table I. Median age at diagnosis was 50 years and a total of 58 patients $(11.0 \%)$ were younger than 35 years. A total of $226(43.4 \%)$ patients were premenopausal. Most tumors were at stage T1-2 (59\%). The median number of metastatic lymph node was 15 (range, 10-95). The majority of the patients (72.5\%) had hormone receptor-positive tumors. The most common subtype was Luminal A (47.4\%), followed by Luminal B (26.7\%), Her2 enriched (15.5\%), and triple negative (10.4\%) subtypes. Patients received anthracycline and taxane-based regimen after surgery. A total of $81.7 \%$ of Her2 positive patients received trastuzumab therapy. A total of $93.4 \%$ patients received radiotherapy.

Effect of breast cancer subtypes on relapse. There were not any significant differences in relapse rates according to molecular subtypes $(\mathrm{P}=0.07)$. Distant relapse rates of subgroups were as follows: $25.2 \%$ for Luminal A, 36\% for Luminal B, $25.9 \%$ for Her2-enriched and 37\% for triple negative subtype. Relapse rates by breast cancer subtype, are shown in Fig. 1 .

DFS according to tumor subtypes. The five year DFS rate was $62 \%$ for the whole study population, $67 \%$ for Luminal A tumors, $53 \%$ for Luminal B tumors, $64 \%$ for Her2 positive tumors and $56 \%$ for triple negative tumors. Luminal A patients 
had better PFS when compared with Luminal $\mathrm{B}(\mathrm{P}=0.026)$ and triple negative $(\mathrm{P}=0.07)$ patients (Fig. 2).

Factors related with DFS. As shown in Table II, pT stage $(\mathrm{P}<0.001)$, operation type $(\mathrm{P}=0.04)$ and biological subtypes were predictors for DFS in univariate analysis. Lymphovascular invasion was prognostic for Her2 enriched tumors.

When these variables were analyzed with Cox proportional hazard model, pT stage $(\mathrm{P}<0.001)$, and breast cancer subtype $(\mathrm{P}<0.001)$, remained significant independent factors for DFS. T4 tumor stage, was a negative prognostic factor for DFS. Patients with Luminal A tumors significantly had longer DFS when compared with Luminal B and triple negative subtypes.

\section{Discussion}

In the present study, we evaluated prognostic value of molecular subtypes for $\mathrm{pN} 3$ breast cancer patients in a large patient population. We showed that, Luminal A subtype was associated with better prognosis as compared to Luminal B and triple negative subtype for pN3a positive breast cancer patients.

Several studies showed that increasing number of $\mathrm{N}$ metastasis is associated with poor prognosis and predicts early relapse after adjuvant chemotherapy (12). However, patients with extensive $\mathrm{N}$ metastasis represent heterogeneous clinical outcomes and identification of prognostic factors is important to detect patients who might require more intensive or less therapy.

It has been shown that, molecular subtypes have impact on response to therapy and survival in breast cancer patients. Early-stage Luminal A breast cancer patients have a better prognosis with a significantly lower relapse rate of $27.8 \%$ as compared with other biological subtypes. In addition, survival from the time of relapse was also longer (13). However, prognostic value of molecular subtypes in patients with extensive $\mathrm{N}$ metastasis is uncertain. A small number of trials evaluated this question. Yang et al (14), found that there was a significant survival difference among patients with $\mathrm{pN} 0-\mathrm{pN} 2$ disease according to breast cancer subtypes in terms of Luminal A breast cancer patients had the best survival outcome when compared with other subtypes. However, molecular subtypes had no prognostic effect on survival for patients with pN3 disease (14). Kim et al (15), evaluated N3 breast cancer patients for prognostic factors and identified young age, high serum neutrophil/lymphocyte ratio ( $>3.0)$, high $\mathrm{N}$ ratio and molecular subgroups as important prognostic factors. They found that patients with the HR+ Her2- subtype had longest DFS while triple negative subtype showed the worst outcome compatible with our findings, however the patient population was relatively small and they did not take into consideration Ki-67 levels when they define molecular subtypes (15).

In our patient population, $41.8 \%$ of patients were Her2 positive. The most commonly diagnosed molecular subtype was Luminal A, while triple negative subtype was rare which consisted of $10.4 \%$ of the patients. There is still controversy regarding the association between breast cancer subtype and lymph node status. Liu et al (16), showed that both TNBC and Luminal A breast cancer subtypes were related with a lower risk of pN3 stage when compared with Luminal B and Her2 overexpression breast cancer subtypes. Proportion of triple negative patients in $\mathrm{pN} 3$ group seems to be low as compared to whole breast cancer population. Although TNBC is more aggressive, it may be related with less frequent involvement of lymph nodes and it is not frequently associated with a pN3 stage disease.

It has been shown that $\mathrm{N} 3$ patients have improved prognosis with novel therapies as compared with old chemotherapy regimens. Taxanes have proven as effective agents in the adjuvant treatment of breast cancer. Adjuvant use of taxanes were evaluated in several randomized clinical trials, and results provided a strong evidence for node positive breast cancer. Three meta-analyses showed that adjuvant anthracycline-based chemotherapy followed by taxane chemotherapy significantly improved DFS and OS rates with an absolute 5-year risk reduction of DFS and OS, 5\% and 3\% respectively (17-19). Emerging data show that the addition of trastuzumab to adjuvant chemotherapy results in durable survival benefits for patients with Her2-positive breast cancer. With a median on-study time of 8.4 years, the addition of trastuzumab resulted in a $37 \%$ improvement in OS and a 40\% improvement in DFS (20). Our patients received anthracycline based chemotherapy followed by taxane treatment. Trastuzumab therapy added to chemotherapy regimen if the patient diagnosed after 2007 with the approval of the drug. This therapy resulted with a 5 year DFS rate 67\% in Luminal A, 53\% in Luminal B, 64\% Her2 positive group and $56 \%$ in triple negative group.

The present study has some limitations. First, surgery was not uniform, as they are performed by different surgeons. Secondly, patients who admitted to hospital from 2003 to 2010 are included in this study and some of the adjuvant therapies do not reflect current clinical practice (e.g., some of the patients with Her2-positive disease did not receive trastuzumab therapy) Therefore, a prospective and randomized controlled trial will be important to validate our findings in this study.

\section{Acknowledgements}

The authors would like to thank Ferhat Yildiz (Department of Public Health, Adnan Menderes University, Aydin, Turkey) for statistical analysis.

\section{Funding}

No funding was received.

\section{Availability of data and materials}

The datasets used and/or analyzed during the current study are available from the corresponding author on reasonable request.

\section{Authors' contributions}

ÖY conceived and designed the study, acquired the patients' data and was a major contributor in writing the manuscript. MAK, AI, NÖ and MA interpreted the patient data on breast cancer treatment and survival. SB revised the manuscript critically for important intellectual content and was a major contributor in writing the manuscript. HIE performed the histological examination of the breast. NM interpreted the molecular characteristics of the breast cancer patients. All authors read and approved the final manuscript. 


\section{Ethics approval and consent to participate}

The present study was approved by Dicle University Ethics Committee (Diyarbakir, Turkey).

\section{Patient consent for publication}

Not applicable.

\section{Competing interests}

The authors declare that they have no competing interests.

\section{References}

1. Amin MB, Edge S, Greene F, Byrd DR, Brookland RK, Washington MK, Gershenwald JE, Compton CC, Hess KR, Sullivan DC, et al (eds): AJCC Cancer Staging Manual. 8th edition. Springer, New York, NY, 2017.

2. Nemoto T, Vana J, Bedwani RN, Baker HW, McGregor FH and Murphy GP: Management and survival of female breast cancer: Results of a national survey by the American College of Surgeons. Cancer 45: 2917-2924, 1980.

3. Walker MJ, Osborne MD, Young DC, Schneebaum S, La Valle GJ and Farrar WB: The natural history of breast cancer with more than 10 positive nodes. Am J Surg 169: 575-579, 1995.

4. Buzdar AU, Kau SW, Hortobagyi GN, Ames FC, Holmes FA Fraschini G, Hug V, Theriault RL, McNeese MD and Singletary SE: Clinical course of patients with breast cancer with ten or more positive nodes who were treated with doxorubicin-containing adjuvant therapy. Cancer 69: 448-452, 1992.

5. Schmoor C, Sauerbrei W, Bastert G, Bojar H and Schumacher M; German Breast Cancer Study Group: Long-term prognosis of breast cancer patients with 10 or more positive lymph nodes treated with CMF. Eur J Cancer 37: 1123-1131, 2001.

6. Basaran G, Devrim C, Caglar HB, Gulluoglu B, Kaya H, Seber S, Korkmaz T, Telli F, Kocak M, Dane F, et al: Clinical outcome of breast cancer patients with N3a ( $\geq 10$ positive lymph nodes) disease: Has it changed over years? Med Oncol 28: 726-732, 2011.

7. Perou CM, Sørlie T, Eisen MB, van de Rijn M, Jeffrey SS, Rees CA, Pollack JR, Ross DT, Johnsen H, Akslen LA, et al: Molecular portraits of human breast tumours. Nature 406: 747-752, 2000

8. Sørlie T, Perou CM, Tibshirani R, Aas T, Geisler S, Johnsen H, Hastie T, Eisen MB, van de Rijn M, Jeffrey SS, et al: Gene expression patterns of breast carcinomas distinguish tumor subclasses with clinical implications. Proc Natl Acad Sci USA 98: 10869-10874, 2001.
9. Sotiriou C, Neo SY, McShane LM, Korn EL, Long PM, Jazaeri A, Martiat P, Fox SB, Harris AL and Liu ET: Breast cancer classification and prognosis based on gene expression profiles from a population-based study. Proc Natl Acad Sci USA 100: 10393-10398, 2003.

10. Abd El-Rehim DM, Ball G, Pinder SE, Rakha E, Paish C, Robertson JF, Macmillan D, Blamey RW and Ellis IO: High-throughput protein expression analysis using tissue microarray technology of a large well-characterised series identifies biologically distinct classes of breast cancer confirming recent cDNA expression analyses. Int J Cancer 116: 340-350, 2005.

11. Yersal O and Barutca S: Biological subtypes of breast cancer: Prognostic and therapeutic implications. World J Clin Oncol 5: 412-424, 2014.

12. Cianfrocca M and Goldstein LJ: Prognostic and predictive factors in early-stage breast cancer. Oncologist 9: 606-616, 2004.

13. Kennecke H, Yerushalmi R, Woods R, Cheang MC, Voduc D, Speers $\mathrm{CH}$, Nielsen TO and Gelmon K: Metastatic behavior of breast cancer subtypes. J Clin Oncol 28: 3271-3277, 2010.

14. Yang ZJ, Yu Y, Hou XW, Chi JR, Ge J, Wang X and Cao XC: The prognostic value of node status in different breast cancer subtypes. Oncotarget 8: 4563-4571, 2017.

15. Kim YY, Park HK, Lee KH, Kim KI and Chun YS: Prognostically distinctive subgroup in pathologic N3 breast cancer. J Breast Cancer 19: 163-168, 2016.

16. Liu N, Yang Z, Liu X and Niu Y: Lymph node status in different molecular subtype of breast cancer: Triple negative tumours are more likely lymph node negative. Oncotarget 8: 55534-55543, 2017.

17. Bria E, Nistico C, Cuppone F, Carlini P, Ciccarese M, Milella M, Natoli G, Terzoli E, Cognetti F and Giannarelli D: Benefit of taxanes as adjuvant chemotherapy for early breast cancer: Pooled analysis of 15,500 patients. Cancer 106: 2337-2344, 2006.

18. De Laurentiis M, Cancello G, D'Agostino D, Giuliano M, Giordano A, Montagna E, Lauria R, Forestieri V, Esposito A, Silvestro L, et al: Taxane-based combinations as adjuvant chemotherapy of early breast cancer: A meta-analysis of randomized trials. J Clin Oncol 26: 44-53, 2008

19. Ferguson T, Wilcken N, Vagg R, Ghersi D and Nowak AK: Taxanes for adjuvant treatment of early breast cancer. Cochrane Database Syst Rev 4: CD004421, 2007.

20. Perez EA, Romond EH, Suman VJ, Jeong JH, Sledge G, Geyer CE Jr, Martino S, Rastogi P, Gralow J, Swain SM, et al: Trastuzumab plus adjuvant chemotherapy for human epidermal growth factor receptor 2-positive breast cancer: Planned joint analysis of overall survival from NSABP B-31 and NCCTG N9831. J Clin Oncol 32: 3744-3752, 2014. 